\title{
Risk factors of poor outcome of pregnancy and delivery in adolescents: a case-control study at the Yaounde Gynaeco-Obstetric and Pediatric Hospital
}

\section{Foumane Pascal*, Belinga Etienne, Hafizatou Mouhaman, Dohbit Julius Sama, Ngo Um Meka Esther, Mboudou Emile Telesphore}

\begin{abstract}
Department Department of Obstetrics and Gynaecology, Faculty of Medicine and Biomedical Sciences, University of
\end{abstract} Yaounde I, Ngoa Ekelle, Yaounde, Cameroon

Received: 30 April 2016

Accepted: 02 June 2016

*Correspondence:

Dr. Belinga Etienne,

E-mail: belingaetienne@yahoo.fr

Copyright: () the author(s), publisher and licensee Medip Academy. This is an open-access article distributed under the terms of the Creative Commons Attribution Non-Commercial License, which permits unrestricted non-commercial use, distribution, and reproduction in any medium, provided the original work is properly cited.

\section{ABSTRACT}

Background: Adolescence is a period of life between 10 and 19 years, marked by a state of psychological imbalance and immaturity of organs. The occurrence of pregnancy at this age group can cause social, psychological or obstetric problems (prematurity, unsafe abortion, obstructed labor). The objective of this study was to identify the risk factors of poor outcome of pregnancy and delivery in adolescents.

Methods: It was a case-control study with a retrolective data collection from January $1^{\text {st }}, 2004$ to December $31^{\text {st }}$, 2013 in the Yaounde Gynaeco-Obstetric and Pediatric Hospital. We included adolescent girls of 11 to 19 years old who delivered in the study site. We compared 128 adolescents of the case group who encountered poor outcome with 128 ones of the control groups with favorable outcome.

Results: At univariate analysis, the number of antenatal care consultations less than four OR: Odds Ratio $(\mathrm{OR}=2.44$ [1.41-4.22]; $\mathrm{P}=0.000)$, the antenatal care consultations done out of our study site $(\mathrm{OR}=1.65(95 \% \mathrm{CI}: 1.00-2.70)$; $\mathrm{p}=0.003)$ and the uterine fundal height less than $33 \mathrm{~cm}$ at the time of childbirth (OR=1.80(95\%CI:1.08-2.98); $\mathrm{p}=0.015)$ were identified as risk factors of poor outcome. After linear logistic regression analysis, the number of antenatal care less than four $(\mathrm{OR}=1.92(1.0-3.56) ; \mathrm{p}=0.037)$ remained as independent risk factor of poor outcome.

Conclusions: The number of antenatal visits less than four is an important risk factor of poor outcome of pregnancy and childbirth in adolescents at the Yaoundé gynaeco-obstetric and pediatric hospital.

Keywords: Risk factor, Poor outcome, Pregnancy, Delivery, Adolescent, Cameroon

\section{INTRODUCTION}

Adolescence is a period of life between 10 and 19 years, marked by a state of psychological imbalance and immaturity of organs. The occurrence of pregnancy at this age group can cause social, psychological or obstetric problems (prematurity, unsafe abortion, obstructed labour). ${ }^{1}$

According to WHO, 16 million girls aged between 15 to 19 years give birth each year worldwide, representing $11 \%$ of all births. Ninety five percent of these births occur in developing countries. ${ }^{2,3}$ The occurrence of pregnancy in adolescence is a source of major social, economic and medical problems both in developed countries and in developing countries. ${ }^{4}$ Poor outcome in pregnancy and childbirth are among the leading cause of death in the girls aged 15 to 19 years in many low income countries. $^{2,3}$

Hence, in order to improve maternal health in adolescents, we aimed to identify the risk factors of poor outcome in pregnancy and childbirth in adolescents 
delivering at the Yaounde Gynaeco-Obstetric and Pediatric Hospital (YGOPH).

\section{METHODS}

It was a case-control study with a retrolective data collection from January $1^{\text {st }}, 2004$ to December $31^{\text {st }}, 2013$ at the Yaounde gynaeco-obstetric and pediatric hospital. We included adolescent girls of 11 to 19 years of age who delivered in the study site. We compared 128 adolescents of the case group who encountered poor outcome with 128 of the control group with favourable outcome. Data were collected using a data sheet, after obtaining ethical clearance from the institution's ethics committee. Parameters of interest were sociodemographic characteristics (age groups, profession, level of education, religion, marital status and Region of origin); obstetric history (gravidity, parity, living or dead children); types of antenatal care (number, site, quality) ; type of labor (spontaneous or induced, duration, mode and duration of membranes rupture, uterine fundal height); mode of delivery (vaginal or caesarean section, vaginal delivery with or without episiotomy, operative or not, type of instrument); poor outcomes during pregnancy (anemia, threatened abortion, intercurrent Infections, preeclampsia, vaginal bleeding, preterm labor, intrauterine fetal death) poor outcomes at delivery (dystocia, perineal tear, preeclampsia, eclampsia, maternal fever, severe bleeding); poor outcomes in the immediate and early post-partum (post-partum hemorrhage, endometritis, anemia) and newborn characteristics (sex, weight, apgar score at 1 and 5 minutes). The data collected were analyzed using Epi Info Version 3.5.4 2012. In assessing the degree of association between the variables studied and the risk of poor outcome in adolescents we calculated the Odds ratio and its $95 \%$ confidence interval. The Fisher exact test and Chi square test were used for comparison of two groups with statistical significance accepted when $\mathrm{P}$ value $<0.05$.

\section{RESULTS}

The two groups were comparable for socio-demographic and obstetric history aspects.

Table 1: Significant variables in pregnancy and childbirth between the cases.

\begin{tabular}{|c|c|c|c|c|}
\hline \multirow[t]{2}{*}{ Variables Cases Controls } & \multicolumn{4}{|c|}{ Control groups. } \\
\hline & OR n $(\%)$ & $P$ value $n=128$ & $\mathrm{n}=128(95 \% \mathrm{CI})$ & Or n $(\%)$ \\
\hline \multicolumn{5}{|l|}{ Number of $* A N C$} \\
\hline$<4$ & $52(40.6)$ & $28(21.9)$ & $2.44(1.41-0.22)$ & 0.000 \\
\hline$\geq 4$ & $76(59.4)$ & $100(78.1)$ & $0.40(0.23-0.70)$ & 0.000 \\
\hline \multicolumn{5}{|l|}{ Sites of ANC } \\
\hline In the study site & $51(39.8)$ & $68(53.1)$ & $0.58(0.35-0.95)$ & 0.022 \\
\hline Out of the study site & $73(57)$ & $57(44.5)$ & $1.65(1.00-2.70)$ & 0.030 \\
\hline None & $4(3.1)$ & $3(2.3)$ & $1.34(0.29-6.12)$ & 0.5 \\
\hline \multicolumn{5}{|l|}{ Term labour /delivery } \\
\hline Yes & $86(67.2)$ & $121(94.5)$ & $0.11(0.05-0.27)$ & 0.000 \\
\hline No & $42(32.8)$ & $7(5.5)$ & $8.44(3.62-19.68)$ & 0.000 \\
\hline \multicolumn{5}{|l|}{ Uterine height } \\
\hline$<33 \mathrm{~cm}$ & $61(47.7)$ & $43(33.6)$ & $1.8(1.08-2.98)$ & 0.015 \\
\hline$(33 \mathrm{~cm}-38 \mathrm{~cm})$ & $63(49.2)$ & $77(60.2)$ & $0.64(0.391 .05)$ & 0.051 \\
\hline$>38 \mathrm{~cm}$ & $4(3.1)$ & $8(6.3)$ & $0.480 .14-1.64)$ & 0.188 \\
\hline \multicolumn{5}{|l|}{ Episiotomy } \\
\hline Yes & $15(11.7)$ & $34(26.6)$ & $0.36(0.18-0.71)$ & 0.001 \\
\hline No & $113(88.3)$ & $94(73.4)$ & $2.72(1.39-5.30)$ & 0.001 \\
\hline \multicolumn{5}{|l|}{ Operative delivery } \\
\hline Yes & $3(2.3)$ & $10(7.8)$ & $0.28(0.07-1.05)$ & 0.042 \\
\hline No & $125(97.7)$ & $118(92.2)$ & $3.53(0.94-13.14)$ & 0.042 \\
\hline \multicolumn{5}{|l|}{ Vacuum extraction } \\
\hline Yes & $1(0.8)$ & $8(6.3)$ & $0.11(0.01-0.95)$ & 0.017 \\
\hline No & $127(99.2)$ & $120(93.8)$ & $8.46(1.04-68.71)$ & 0.017 \\
\hline
\end{tabular}

*ANC: Antenatal care consultations 
In the analysis of variables (Table 1), the number of antenatal care consultations less than four multiplied by 2.4 the risk of poor outcome $[\mathrm{p}=0.000 ; \mathrm{OR}=2.44(\mathrm{CI}=$ 1.41 to 4.22$)$ ]. Having done antenatal care consultations elsewhere out of the Yaounde gynaeco-obstetrics and pediatric hospital increased by 1.65 folds the risk of poor outcome $[\mathrm{p}=0.030 ; \mathrm{OR}=1.65(1.00-2.70)]$ and uterine fundal height less than $33 \mathrm{~cm}$ at the time of delivery multiplied by 1.8 the risk of poor outcome $[\mathrm{p}=0.015$; $\mathrm{OR}=1.8(1.08-2.98)]$. In contrary, the two groups were comparable for quality of antenatal care consultations, type, duration of membrane rupture and duration of labour. There was 6 folds more risk of low birth weight in the poor outcome group $[\mathrm{p}=0.000 \mathrm{OR}=6.10(\mathrm{CI}=2.59$ 14.38)].

\section{Childbirth Features among adolescents}

In analysing delivery characteristics ((Table 2), the following were noticed: delivering at term increased by about 8.5 folds the chance of favourable outcome in the control group $[\mathrm{p}=0.000 ;$ OR $=8.44$ (3.62-19.68)]. As protective factors we had: the use of episiotomy [p = $0.001 ; \mathrm{OR}=0.36(\mathrm{CI}=0.18-0.71)]$ and vacuum extraction $[\mathrm{p}=0.042 ; \mathrm{OR}=0.28(\mathrm{CI}=0.071 .05)]$.

Table 2: Risk factors in univariate logistic regression analysis.

\begin{tabular}{|lccc|}
\hline Variables & OR & $95 \%$ CI & P value \\
\hline *ANC <4 & 2.44 & $(1.41-4.22)$ & 0.000 \\
\hline $\begin{array}{l}\text { *ANC elsewhere out } \\
\text { of study site }\end{array}$ & 1.65 & $(1.00-2.70)$ & 0.030 \\
\hline $\begin{array}{l}\text { Uterine fundal height } \\
\text { <33cm }\end{array}$ & 1.79 & $(1.08-2.98)$ & 0.015 \\
\hline Delivery at term & 0.11 & $(0.05-0.27)$ & 0.000 \\
\hline Episiotomy & 0.36 & $(0.18-0.71)$ & 0.001 \\
\hline vacuum extraction & 0.11 & $(0.01-0.95)$ & 0.017 \\
\hline Low birth weight & 6.10 & $(2.59-14.38)$ & 0.000 \\
\hline
\end{tabular}

Table 3: Independant risk factors after logistic regression.

\begin{tabular}{|lcc|c|}
\hline Variables & OR & $95 \%$ CI & P value \\
\hline *ANC < 4 & 1.92 & $(1.03-3.56)$ & 0.037 \\
\hline $\begin{array}{l}* \text { ANC out of study } \\
\text { site }\end{array}$ & 1.35 & $(0.77-2.34)$ & 0.285 \\
\hline **UH < 33cm & 1.39 & $(0.77-2.49)$ & 0.265 \\
\hline Term delivery & 0.16 & $(0.06-0.41)$ & 0.000 \\
\hline Vacuum extraction & 0.18 & $(0.02-1.59)$ & 0.124 \\
\hline $\begin{array}{l}\text { Episiotomy } \\
\text { *ANC: Antenatal care consultations ; **UH : Uterine Fundal }\end{array}$ \\
$\begin{array}{l}\text { Height } \\
\text { He.37 }\end{array}$ & $(0.17-0.78)$ & 0.009 \\
\hline
\end{tabular}

After logistic linear regression, confounding factors were eliminated (Table 3). The significant risk factor of poor outcome in pregnancy and childbirth of adolescents mother was the number of antenatal care visits below four (or =1.92 [1.03-3.56]; $\mathrm{P}=0.037$ ). It was found that delivery at term (or $=0.16[0.06-0.41] ; \mathrm{P}=0.000)$ and episiotomy at childbirth (or=0.37 [0.17-0.78]; $\mathrm{P}=0.009$ ) were protective factors against poor outcome.

\section{Types of poor outcome}

These were mainly (Table 4) intercurrent infections 23 (57.50\%) malaria being the leading infection (95.70\%) and anemia $8(20 \%)$ ] during pregnancy; Perineal tears 47 (64.40\%), preeclampsia/eclampsia 18(24,60\%) at delivery; postpartum hemorrhage 6(40\%) and endometritis $5(33.30 \%)$ in the immediate and early postpartum.

Table 4: Significant poor outcome in pregnancy and delivery.

\begin{tabular}{|lll|}
\hline Variables & Number & $\%$ \\
\hline During pregnancy & & \\
\hline Intercurrent infections & 23 & 57.50 \\
\hline Anemia & 8 & 20.00 \\
\hline Intrauterine fetal death & 6 & 15.00 \\
\hline Preterm labour & 6 & 15.00 \\
\hline Preeclampsia & 3 & 7.50 \\
\hline Threathened abortion & 1 & 2.50 \\
\hline Vaginal bleeding & 1 & 2.50 \\
\hline At delivery & & \\
\hline Perineal tear & 47 & 64.40 \\
\hline Preeclampsia/eclampsia & 18 & 24,65 \\
\hline Dystocia & 10 & 13.70 \\
\hline Maternal Fever & 2 & 2.74 \\
\hline Placenta abruptio & 1 & 1.40 \\
\hline Post-partum complications & & \\
\hline Post-Partum haemorrhage & 6 & 40.00 \\
\hline Endometrits & 5 & 33.30 \\
\hline Anemia & 4 & 26.70 \\
\hline Preeclampsia/eclampsia & 1 & 6.70 \\
\hline
\end{tabular}

\section{DISCUSSION}

The WHO recommends four antenatal care visits during pregnancy with specific activities whose effectiveness is scientifically proven. ${ }^{5}$ Our findings were in complete agreement with these recommendations. Indeed, in our study, the number of antenatal care consultations less than four was associated with an increase of about 2.5 times the risk of poor outcome (or $=2.44$; [1.41-4.22]). It is during antenatal care consultations that pregnant women are educated about the warning signs and dangers of complications. They are offered screening and early treatment of patologies. Care during childbirth is 
therefore improved. ${ }^{6}$ Our results were consistent with those of Kongnyuy et al. ${ }^{7}$ Who studied in perinatal outcomes among adolescents, they found that in addition to the number of antenatal care consultations less than four, maternal age and lack of employment were risk factors of adverse perinatal outcomes. Chiabi et al. ${ }^{8}$ identified the maternal age below 20 years, primiparity and the number of antenatal care consultations less than four as risk factors of low birth weight. Unlike these two studies, we have not found maternal age nor lack of employment as risk factor of poor outcome. Some authors have compared the evolution of pregnancy among adolescents and adults. According to Mahfouz et al, having made as many antenatal care consultations as women aged $20-35$ years $(6.6 \pm 1.1$ against $6.7 \pm 1.2$ on average) the adolescent no longer represents a group at risk of adverse neonatal outcomes, especially if adequate antenatal care were provided. ${ }^{9}$ Our results point out the number of consultations visit as a significant risk factor of poor outcome. Again, for Kurth et al, when performing fewer antenatal care consultations compared to adult mothers adolescents were at risk of having babies with a small birth weight $(3.3 \pm 1.9$ against $4.4 \pm 1.9$ on average; $\mathrm{P}$ $<0.01) .{ }^{10}$ Our study showed a 6 folds increased risk of low birth weight in the poor outcome group. Bulkumez et al. emphasized on the need of sufficient antenatal care consultations which reduces the occurrence of poor outcome. ${ }^{11}$ According to Léticée et al, women with little or no follow up have a high risk of poor outcome of the pregnancy, particularly perinatal death (OR adjusted $=$ $7.85 ;[2.80-22.02])$ and prematurity (OR adjusted $=7.85$; $[2.80-22.02]) .^{12}$ In our study, more than half $(57 \%)$ did their antenatal care consultations elsewer out of the study site $(\mathrm{OR}=1.65 ;[1.00-2.70] ; \mathrm{P}=0.030)$. After linear logistic regression, this factor was not retained as a significant risk factor of poor outcome. According to Mburano, the quality of antenatal care consultations is different from a health facility to another, from a health district to another and from public to private. ${ }^{13}$ Antenatal services in public health facilities do not provide optimum satisfaction while the informal clinics focus on the profit not in accordance with the competence and the quality of care. ${ }^{14,15}$ It would therefore be desirable to do antenatal care visits at the place of delivery for the guarantee of care and prevention of poor outcomes. Uterine size less than $33 \mathrm{~cm}$ at the time of delivery was associated with an increased risk of poor outcome (or = 1.8; [1.08-2.98]; $\mathrm{P}=0.015)$. These results corroborate with those of Adjahoto et al who stated that low gestational weight may be suspected if the uterine height at admission in the labor ward is less than or equal to 32 cm. ${ }^{16}$ Births occurred between 37 to 42 weeks $(80.9 \%)$ of which $94.5 \%$ in the control group and $67.1 \%$, in the case group (or $=0.11 ;[0.05-0.27] ; \mathrm{P}=0.000$ ). These results corroborate with those of Iloki et al; Jérome; Geist et al stating that childbearing in adolescent girls is mostly at term (17-19) in contrary with authors like Mukhopadhyay et al; Omole-Ohosi et al; Thaithae et al, who have found more risk of premature birth in adolescent mothers. ${ }^{20-22}$
The practice of episiotomy during vaginal birth prevented poor outcomes (or $=0.36 ;[0.180 .71] ; \mathrm{P}=0.001$ ) as it was shown by Enyindah et al to prevent third degree and complete perineal tears. ${ }^{23}$ According to Räisänen et al, episiotomy decreases the risk of rupture of the anal sphincter in primiparous women or $=0.83[0.75-0.92]){ }^{24}$ Our results showed an association with a favourable outcome in operative vaginal delivery (or $=0.28$; $[0.07$ $1.05] ; \mathrm{P}=0.042)$, particularly the use of vacuum extraction (or $=0.11$ [0.01- 0.95]; $\mathrm{P}=0.017$ ). According to Anate in Nigeria, the use of vacuum extraction is associated with less maternal birth canal trauma and less neonatal mortality compared to when the forceps is used. $^{25}$ According to Räisänen et al, vacuum extraction plus episiotomy in primiparous women at expulsion reduced the risk of rupture of the anal sphincter (or $=0.70$ $[0.57-0.85]) .^{24} \mathrm{Nkwabong}$ et al, did not find any influence of type of the instrument used, on the Apgar scores of newborns be it vacuum extraction or forceps. Their poor maternal outcomes were minor, represented by vaginal and perineal tears. ${ }^{26}$

\section{CONCLUSION}

After univariate analysis, the number of antenatal care consultations fewer than four, the antenatal care consultations done out of the Yaounde gynaeco-obstetric and pediatric hospital and the uterine height less than 33 $\mathrm{cm}$ at the labour room were identified as risk factors of poor obstetrical outcome. After linear logistic regression, the only significant risk factor of poor outcome was the antenatal care consultations less than four.

\section{Funding: No funding sources \\ Conflict of interest: None declared}

Ethical approval: The study was approved by the Institutional Ethics Committee

\section{REFERENCES}

1. Nguembi E. Yanza MC. Sepou A. PoussoumandjiGuezza MA. Nali MN. Zohoun T. The adolescent pregnancy in the city of Bouar (central Africa). Médecine Afr Noire. 2005;5212:681-5.

2. Early marriages. Adolescent and young women pregnancy. Sixty-fifth World Health Assembly A65 / 13. paragraph 13.4 of the provisional agenda March 2012.

Available

at: http://apps.who.int/gb/ebwha/pdf_files/WHA65/A65 _13-fr.pdf.

3. WHO I. The adolescent pregnancy. Available at http://www.who.int/mediacentre/factsheets/fs364/en/

4. Meram E. Abdemouniam A. The adolescent mother and child. Available at http://www.santemaghreb.com/maroc/mop19.htm.

5. JVPB WHO antenatal care randomized trial: manual for the implementation of the new model. Available athttp://www.who.int/reproductivehealth/publication s/RHR_01_30/RHR_01_30.pdf. 
6. Prual A, De Bernis L, El Joud DO. Potential role of prenatal care in reducing maternal and perinatal mortality in sub-Saharan Africa. J Gynécologie Obstétrique Biol Reprod. 2002;31(1):90-9.

7. Kongnyuy EJ, Nana PN, Fomulu N, Wiysonge SC, Kouam L, Doh AS. Adverse perinatal outcomes of adolescent pregnancies in Cameroon. Matern Child Health J. 2008;12(2):149-54.

8. Chiabi A, Miaffo L, Mah E, Nguefack S, Mbuagbaw L, Tsafack J, et al. Risk factors and prognosis of hospital neonatal low birth weight (birth weight less than 2500 grams) in the Yaounde gyneco-obstetrics and pediatric hospital. Cameroon J Pédiatrie Puériculture. 2011;24(3):125-32.

9. Mahfouz AAR, El-Said MM, Al-Erian RAG, Hamid AM. Teenage pregnancy: are teenagers a high risk group? Eur J Obstet Gynecol Reprod Biol. 1995;59(1):17-20.

10. Kurth F, Bélard S, Mombo-Ngoma G, ScUHster K, Adegnika AA, Bouyou-Akotet MK, et al. Adolescence as risk factor for adverse pregnancy outcome in Central Africa: a crosssectional study. PloS One. 2010;5(12):e14367.

11. Bukulmez O, Deren O. Perinatal outcome in adolescent pregnancies: a cases-control study from a Turkish university hospital. Eur J Obstet Gynecol Reprod Biol. 2000;88(2):207-12.

12. Léticée N, Vendittelli F, Janky E. Prognostic value of the quality of prenatal care on perinatal outcomes in Guadeloupe. J Gynécologie Obstétrique Biol Reprod. 2004;33(1):80-1.

13. Mburano R. The quality of antenatal care consultations from the perspective of customers in Cameroon in the districts of Nkongsamba, Bafang and Mfou. Afr Popul Stud. 2007;22:23-46.

14. INS second tracking survey of public spending and the level of satisfaction in the areas of education and health in Cameroon (PETS2). Available at: http://www.statisticsCameroon.org/downloads/pets/2 /Rapport_principal_Sante_francais.pdf.

15. Bonono RC. Ongolo-Zogo P. Optimize the use of antenatal care consultations in Cameroon. Development Center of best practices in healthCentral Hospital. Yaoundé Cameroon 2012. Available at: http://cdbph.org/documents/PolicyBriefs_Optimiser_ lutilisation_des_services_de_consultatio n_prenatale_au_Cameroun.pdf.
16. Adjahoto EO, Gogovor Y, Hodonou KA. Use of the ROC (receiver operating characteristic) curve in the prediction of fetal hypotrophy with uterine height measurement. J Gynécologie Obstétrique Biol Reprod. 1999;28(5):472-5.

17. Lucile J. The adolescent pregnancy. Available at http://dumas.ccsd.cnrs.fr/docs/00/55/57/75/PDF/me moire_jerome.pdf.

18. Iloki LH, Koubaka R, Itoua C, Moutounou GM. Adolescent pregnancy and delivery: 276 cases observed at the Brazzaville University Hospital. Congo. J Gynécologie Obstétrique Biol Reprod. 2004;33(1):37-42.

19. Geist RR. Beyth Y. Shashar D. Beller U. Samueloff A. Perinatal outcome of teenage pregnancies in a selected group of patients. J Pediatr Adolesc Gynecol. 2006;19(3):189-93.

20. Mukhopadhyay P, ChaudUHri RN, Paul B. Hospital based perinatal outcomes and poor outcomes in teenage pregnancy in India. J Health Popul Nutr. 2010;28(5):494-500.

21. Omole-Ohonsi A, Attah RA. Obstetric outcome of teenage pregnancy in Kano. North Western Nigeria. West Afr J Med. 2010;29(5):318-22.

22. Thaithae S, Thato R. Obstetric and perinatal outcomes of teenage pregnancies in Thailand. J Pediatr Adolesc Gynecol. 2011;24(6):342-6.

23. Enyindah CE, Fiebai PO, Anya SE, Okpani AOU. Episiotomy and perineal trauma prevalence and obstetric risk factors in Port Harcourt. Nigeria Niger J Med J Natl Assoc Resid Dr Niger. 2007;16(3):242-5.

24. Räisänen SH, Vehviläinen-Julkunen K, Gissler M, Heinonen S. Lateral episiotomy protects primiparous but not multiparous women from obstetric anal sphincter rupture. Acta Obstet Gynecol Scand. 2009;88(12):1365-72.

25. Anate M. Instrumental (operative) vaginal deliveries: vacuum extraction compared with forceps delivery at Ilorin University Teaching Hospital. Nigeria. West Afr J Med. 1991;10(2):127-36.

26. Nkwabong E, Nana PN, Mbu R, Takang W, Ekono MR, Kouam L. Indications and maternofetal outcome of operative deliveries at the University Teaching Hospital of Yaounde. Cameroon. Trop Doct. 2011;41(1):5-7.

Cite this article as: Pascal F, Etienne B, Mouhaman H, Sama DJ, Esther NM, Telesphore ME. Risk factors of poor outcome of pregnancy and delivery in adolescents: a case-control study at the Yaounde Gynaeco-Obstetric and Pediatric Hospital. Int J Reprod Contracept Obstet Gynecol 2016;5:2228-32. 